Jurnal Pemberdayaan: Publikasi Hasil Pengabdian kepada Masyarakat

Vol. 2, No. 1, April 2018, Hal. 143-150

ISSN: 2088 4559; e-ISSN: XXXX-XXXX

DOI:

\title{
PEMBERDAYAAN MASYARAKAT \\ MELALUI KEWIRAUSAHAAN DAN GERAKAN SEHAT DI KELURAHAN BAUSASTRAN, KECAMATAN DANUREJAN, KOTA YOGYAKARTA
}

\author{
Rina Ratih, Ikhtiarso \\ Universitas Ahmad Dahlan, Yogyakarta \\ rinaratihuad@yahoo.com
}

\begin{abstract}
ABSTRAK
Permasalahan yang ada di masyarakat Kelurahan Bausatran, Kecamatan Danurejan, Kota Yogyakarta adalah terbatasnya pengetahuan ibu-ibu penjual kue-kue tradisional tentang kewirausahaan dan kurangnya kesadaran masyarakat tentang pentingnya kesehatan. Oleh karena itu, program mahasiswa KKN Alternatif UAD fokus pada upaya pemberdayaan kewirausahaan dan kesehatan. Program ini bertujuan memberdayakan ibu-ibu pedagang kue tradisional dan meningkatkan kesadaran masyarakat pada bidang kesehatan. Metode pelaksanaan program meliputi metode ceramah dan praktek. Hasil dan dampak dari kegiatan mahasiswa KKN bagi masyarakat di Kelurahan Bausastran ini adalah (1) peningkatan pengetahuan ibu-ibu tentang kewirausahaan dan (2) peningkatan kesadaran masyarakat terhadap gerakan hidup sehat.
\end{abstract}

Kata Kunci: pemberdayaan, masyarakat, kewirausahaan, kesehatan

\begin{abstract}
The problems that exist in the community of Bausatran Subdistrict, Danurejan Subdistrict, Yogyakarta City are the limited knowledge of traditional cake seller mothers about entrepreneurship and lack of public awareness about the importance of health. Therefore, the UAD Alternative KKN student program focuses on efforts to empower entrepreneurship and health. This program aims to empower traditional cake traffickers and increase public awareness in the health sector. Methods of implementing the program include lecture methods and practice. The results and impact of KKN student activities for the community in Bausastran Village are (1) increasing knowledge of mothers about entrepreneurship and (2) increasing public awareness of the movement of healthy living.
\end{abstract}

Keywords: empowerment, community, entrepreneurship, health 


\section{PENDAHULUAN}

Kelurahan Bausasran merupakan salah satu kelurahan yang berada di Kecamatan Danurejan, Kota Yogyakarta. Lokasi yang menjadi tempat pelaksanaan kegiatan mahasiswa Kuliah Kerja Nyata Alternatif 58 bertempat di Musholla AtTaubah Rt 48 Rw 12 Bausaran, Danurejan, Yogyakarta. Lokasi tersebut berbatasan dengan Kampung Ronodikdayan. Kelurahan ini terletak di perkotaan. Potensi sumber daya manusia yang ada di Kelurahan ini pada umumnya adalah wirausaha, seperti pembuatan kue tradisional. Kue tradisional atau jajanan pasar ada yang dibuat sendiri ada juga yang menerima titipan dari orang lain. Maraknya kue-kue modern dengan kemasan yang lebih menarik membuat kue-kue trandisional kurang diminati. Maka yang menjadi permasalahan di lokasi ini adalah daya beli masyarakat terhadap kue-kue tradisona menurun. Hal ini sebabkan oleh terbatasnya pengetahuan dan keterampilan pembuat kue-kue tradisional. Kurangnya kreativitas mengolah bahan lokal menjadi kue-kue yang lebih menarik.

Permasalahan lain yang dihadapi adalah kurangnya kesadaran masyarakat terhadap kesehatan. Masih ditemukan sikap-sikap masyarakat yang kurang peduli pada sampah di lingkungan masing-masing. Masih banyak halaman rumah yang kosong dan tidak dimanfaatkan. Maka kegiatan yang diselenggarakan oleh mahasiswa KKN adalah penyuluhan usaha dengan modal kecil, pelatihan pembuatan aneka kue, penyuluhan peduli lingkungan, penyuluhan pola hdup sehat, penyuluhan kesehatan, penyuluhan dagusibu, dan pelatihan apoteker cilik

Menurut Melicher (2015) dalam buku Entrepreneurial Finance bahwa kewirausahaan adalah sebuah proses dalam merubah ide menjadi kesempatan komersil dan menciptakan nilai (harga) "Process of changing ideas into commercial opportunities and creating value". Pendapat ini mengungkapkan bahwa proses itu menjadi hal yang sangat penting. Menurut Soegoto (2009) bahwa kewirausahaan atau entrepreneurship adalah usaha kreatif yang dibangun berdasarkan inovasi untuk menghasilkan sesuatu yang baru, memiliki nilai tambah, memberi manfaat, menciptakan lapangan kerja dan hasilnya berguna bagi orang lain. Jiwa wirausaha ini sesungguhnya sudah dimiliki oleh ibu-ibu di Kelurahan 
Bausastran, Kecamatan Danurejan ini. Oleh karena itu, perlu dikembangkan dan diberi motivasi untuk terus berkreativitas membuat olahan kue-kue tradisional menjadi menarik dan meningkatkan daya beli masyarakat.

\section{METODE}

Metode menurut Sanjaya (2010) merupakan cara yang digunakan untuk mengimplementasikan sebuah rencana yang disusun sebelumnya dalam kegiatan nyata agar sesuai dengan tujuan awal dan berhasil secara optimal. Beberapa metode yang digunakan dalam pelatihan ini yaitu:

1. Ceramah

Metode ceramah digunakan untuk menyampaikan materi secara lisan atau verbal dengan media suara dan fasilitator. Dalam pelatihan ini metode ceramah digunakan ketika diawal sesi untuk menyampaikan materi secara umum.

\section{Praktek}

Metode ini merupakan salah satu upaya dalam memberikan pengalaman langsung kepada peserta. Metode ini digunakan pada saat kegiatan pelatihan setelah peserta mendapatkan teori.

Kegiatan-kegiatan penyuluhan dan pelatihan ini dilakukan selama dua hari, yaitu 89 Desember 2017. Alat dan bahan yang digunakan dalam pelatihan pembuatan kuekue tradisional sebagaimana biasanya yaitu peralatan memasak seperti kompor, panci, dan dandang untuk mengukus, sedangkan bahan-bahannya berupa terigu, gula, telor, coklat, dan lain-lain. Ringkasan metode pelaksanaan beserta jam kerja efektif mahasiswa (JKEM) dapat dilihat pada tabel di bawah ini.

Tabel 1. Program tematik, JKEM, dan jumlah mahasiswa

\begin{tabular}{|c|c|l|c|c|}
\hline No & Metode & \multicolumn{1}{|c|}{ Kegiatan } & JKEM & $\begin{array}{c}\sum \text { mhs } \\
\text { terlibat }\end{array}$ \\
\hline 1 & Ceramah & $\begin{array}{l}\text { Penyuluhan kewirausahaan: } \\
\text { usaha dengan modal kecil }\end{array}$ & $1 \times 50 ”$ & 27 \\
\hline
\end{tabular}

Pemberdayaan Masyarakat Melalui Kewirausahaan dan Gerakan Sehat (Rina Ratih)| 145 


\begin{tabular}{|c|c|c|c|c|}
\hline & & $\begin{array}{l}\text { Penyuluhan peduli lingkungan } \\
\text { bagi masyarakat }\end{array}$ & $1 \times 50^{\prime}$ & 27 \\
\hline & & $\begin{array}{l}\text { Penyuluhan pola hidup sehat } \\
\text { bagi masyarakat }\end{array}$ & $1 \times 50$ & 27 \\
\hline & & $\begin{array}{l}\text { Penyuluhan Dagusibu bagi ibu- } \\
\text { ibu }\end{array}$ & $1 \times 50$ & 27 \\
\hline \multirow[t]{4}{*}{2.} & Praktek & $\begin{array}{l}\text { Pelatihan apoteker cilik bagi } \\
\text { anak-anak dan remaja }\end{array}$ & $2 \times 100$ & 27 \\
\hline & & $\begin{array}{l}\text { Pembuatan kue: Brownis bagi } \\
\text { ibu-ibu }\end{array}$ & $2 \times 150 "$ & 27 \\
\hline & & $\begin{array}{l}\text { Pembuatan kue: Karangsemut } \\
\text { bagi ibu-ibu }\end{array}$ & $2 \times 150 "$ & 27 \\
\hline & & Pelatihan penanaman TOGA & $2 \times 100$ & 27 \\
\hline
\end{tabular}

\section{HASIL, PEMBAHASAN, DAN DAMPAK}

Kelurahan Bausasran memiliki rencana pembangunan dari segi infrastruktur dan perekonomian. Selain itu, Kampung Bausasran sebagai perlintasan jalur alternatif menuntut kampung ini mampu menjadi kampung yang berkelanjutan. Sehingga papan rambu-rambu lalulintas juga diperlukan. Perekonomian juga menjadi perencanaan pembangunan Kampung Bausasran. Hampir sebagian besar penduduk Kampung Bausasran bekerja sebagai wiraswasta.

Hubungan Sosial dan Budaya di Kelurahan Buasastran sangat baik. Kondisi lingkungan di kelurahan tersebut dapat dikatakan sangat akrab dan penuh kekeluargaan. Semua itu dibangun dari adanya beberapa kegiatan-kegiatan yang dilakukan bersama secara teratur dan berkesinambungan. Demografi penduduk Jumlah penduduk laki-laki ada 156 jiwa. Perempuan ada 148 jiwa. Total 304 jiwa. Komposisi penduduk berdasarkan agama yang ada di Kelurahan Bausastran adalah sebagai berikut: Islam (272 jiwa), Kristen (14 jiwa), Katolik (18 Jiwa), 
Program-program mahasiswa KKN UAD menyesuaikan dengan permasalahan dan kebutuhan masyarakat yaitu berupa penyuluhan usaha dengan modal kecil, penyuluhan peduli lingkungan, penyuluhan pola hdup sehat, penyuluhan kesehatan, penanaman TOGA, penyuluhan dagusibu, dan pelatihan apoteker cilik. Penyuluhan-penyuluhan ditujukan bagi masyarakat, baik ibu-ibu maupun bapak-bapak, sedangkan pelatihan pembuatan kue ditujukan bagi ibu-ibu, dan pelatihan apoteker cilik ditujukan bagi anak-anak dan remaja.

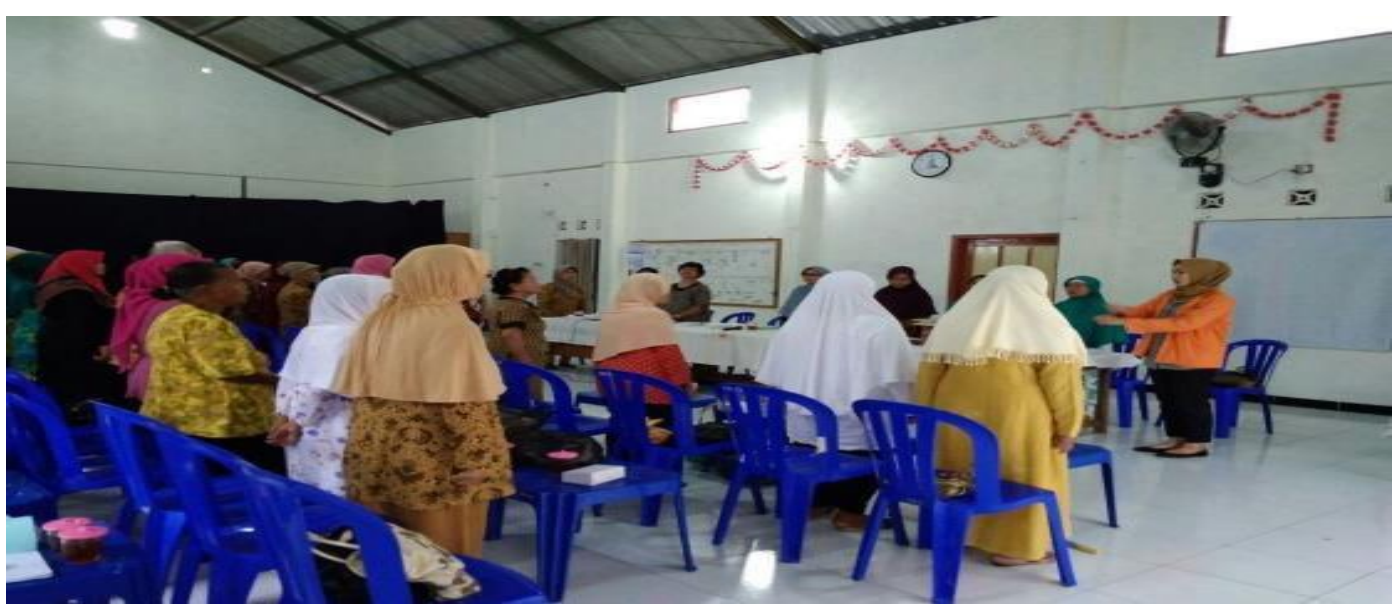

Gambar 1. Pelatihan Pembuatan Kue

Penyuluhan DAGUSIBU Program ini memberikan informasi dan melatih cara mendapatkan, menggunakan, menyimpan, dan membuang obat yang baik yang ditujukan untuk ibu-ibu di RW 11 Bausasran. Tujuannya agar meningkatkan kesadaran pentingnya penggunaan obat yang baik dan benar di RW 11 Bausasran. 


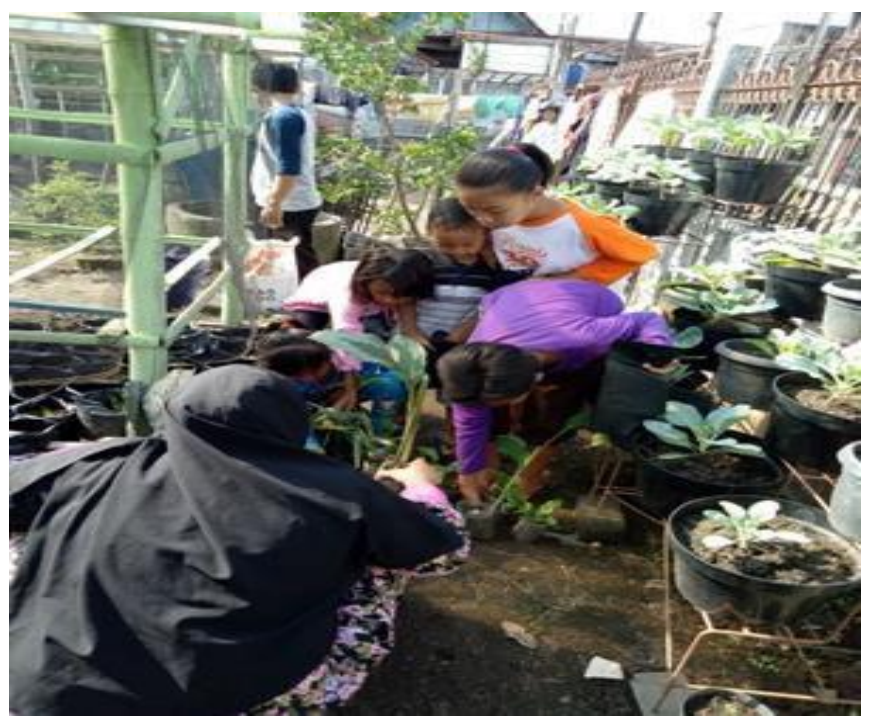

Gambar 2. Pelatihan penanaman TOGA

Penyuluhan dan pelatihan penanaman TOGA bagi ibu-ibu. Tujuan pembudidayaan TOGA ini adalah untuk mengenali nama-nama, manfaat TOGA, dan kegunaanya serta cara perawatan tanaman. TOGA sebagai obat alami dapat juga digunakan untuk mengobati berbagai penyakit. Tanaman Obat Keluarga yang di budidayakan cukup banyak dari jahe hingga sereh. Budidaya tanaman obat di halaman rumah atau pekarangan sebagai antisipasi pencegahan maupun mengobati secara mandiri menggunakan tanaman obat yang ada. Sedangkan tanaman obat sendiri adalah tanaman yang sebagian atau seluruh tanamannya dimanfaatkan sebagai obat, bahan atau ramuan obat.

Menurut Nugraha (2015) dalam bidang tanaman obat, Indonesia dikenal sebagai salah satu negara yang memiliki keanekaragaman hayati terbesar kedua setelah Brazil, sehingga sangat potensial dalam mengembangkan tanaman obat yang berbasis pada tanaman obat kita sendiri. Indonesia kaya akan aneka ragam tanaman obat. Lebih dari 1000 spesies tumbuhan dapat dimanfaatkan sebagai bahan baku obat, oleh karena itu budidaya tanaman obat di Indonesia 


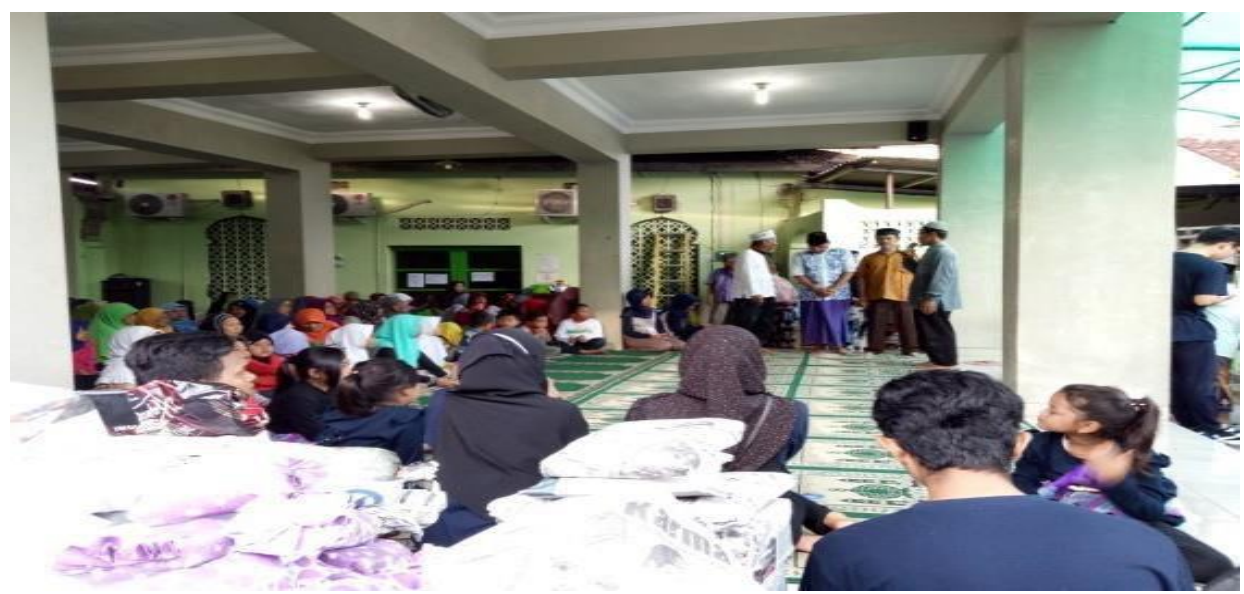

Gambar 3. Kegiatan penyuluhan TOGA

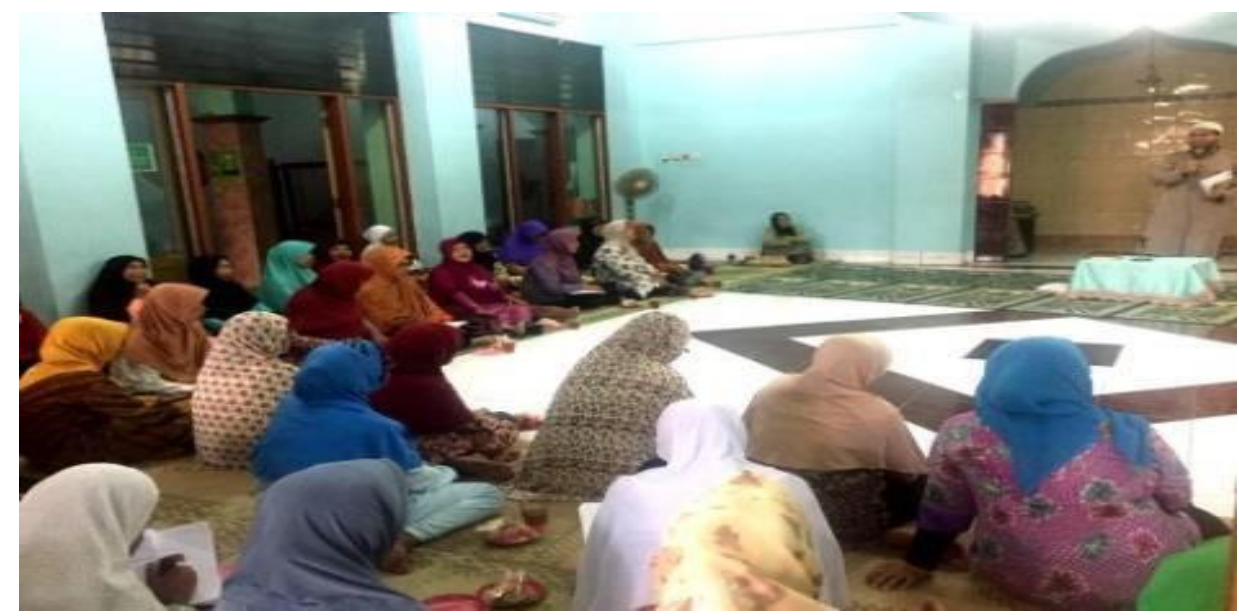

Gambar 4. Penyuluhan DAGUSIBU

Penyuluhan DAGUSIBU bagi masyarakat. Program ini memberikan informasi dan melatih cara mendapatkan, menggunakan, menyimpan, dan membuang obat yang baik yang ditujukan untuk ibu-ibu di RW 11 Bausasran. Tujuannya agar masyarakat meningkat kesadarannya tentang pentingnya penggunaan obat yang baik dan benar.

Setelah masyarakat khususnya ibu-ibu dan remaja putri mengikuti pelatihan, dampak dari kegiatan ini adalah (1) peningkatan pengetahuan masyarakat tentang pentingnya kewirausahaan, (2) peningkatan kesadaran masyarakat terhadap kesehatan khsususnya gerakan hidup sehat. 


\section{SIMPULAN}

Berbagai kegiatan berupa penyuluhan dan pelatihan yang diberikan kepada masyarakat sangat bermanfaat. Penyuluhan-penyuluhan yang diberikan menambah wawasan masyarakat, baik tentang wirausaha maupun tentang kesehatan. Pelatihan pembuatan olahan kue tradisional bagi ibu-ibu pedagang kue sangat bermanfaat. Dampaknya dapat meningkatkan pendapatkan ekonomi keluarga. Demikian pula penyuluhan tentang kesehatan dan penanaman TOGA, dampaknya sangat bermanfaat bagi keluarga agar tetap sehat dan sejahtera.

\section{DAFTAR PUSTAKA}

Milicher R., 2015. Entrepreunerial Finance. Diunduh di http://hariannetral.com/2015/06/pengertian-kewirausahaan-dan-wirausahaserta-ciri-dan-tujuannya.html

Nugraha, S. P., Rusma W. A., 2015. Pelatihan Penanaman Tanaman Obat Keluarga. Yogyakarta: Universitas Islam Indonesia.

Sanjaya, W. 2010. Strategi Pembelajaran Berorientasi Standar Proses Pendidikan. Jakarta: Kencana

Soegoto, E. S., 2009. Enterpreneurship, Menjadi Pebisnis Ulung. Jakarta: Gramedia. 